\title{
Hydrogen evolution catalyzed by a water-soluble cobalt(II) complex with picolinic acid ions
}

Ling-Zhi Fu, Ling-Zhi Tang, Yun-Xiao Zhang, Qian-Nan Liang, Chang Fang, Shu-Zhong Zhan*

College of Chemistry and Chemical Engineering, South China University of Technology, Guangzhou 510640, China.

\begin{abstract}
:
A new molecular catalyst based on cobalt(II) complex $\left[\mathrm{CoA}_{2}\left(\mathrm{H}_{2} \mathrm{O}\right)_{2}\right] \mathbf{1}$ (A: picolinic acid ion) is prepared by the reaction of picolinic acid (HA) with $\mathrm{CoCl}_{2} \cdot 6 \mathrm{H}_{2} \mathrm{O}$. Electrochemical studies indicate $\mathbf{1}$ is a homogeneous electrocatalyst for water reduction in a purely aqueous medium. $\mathbf{1}$ can catalyze hydrogen evolution from water with a turnover frequency (TOF) of 350.6 moles of hydrogen per mole of catalyst per hour at an overpotential of $687.6 \mathrm{mV}$ (in buffer, $\mathrm{pH}$ 7.0).
\end{abstract}

Keywords: Cobalt(II) complex; molecular electrocatalyst; water reduction; hydrogen evolution.

* Corresponding author. Fax: +862087112053.

E-mail address: shzhzhan@scut.edu.cn (S.-Z. Zhan). 


\section{Introduction}

Hydrogen is one of the most ideal energy in the future, because of its numerous advantages such as recyclability and pollution-free use [1-3]. Water is the only waste-free electron-source substrate that could sustain the scale of the process required to supply our energy demands. Thus water splitting is an important method for hydrogen production in high purity and large quantities [4]. And electrolysis of water is the simplest way to produce hydrogen. However, the kinetically slow oxygen evolution reaction (OER) $2 \mathrm{H}_{2} \mathrm{O} \rightarrow 4 \mathrm{H}^{+}+\mathrm{O}_{2}+4 \mathrm{e}^{-}$(in acid) or $4 \mathrm{OH}^{-} \rightarrow 2 \mathrm{H}_{2} \mathrm{O}+\mathrm{O}_{2}+$ $4 \mathrm{e}^{-}$(in base) represents a significant efficiency loss in water-splitting systems $[5,6]$. To increase the reaction rate, it is necessary to use an efficient hydrogen evolution reaction (HER) electrocatalyst. Therefore, many research groups, including ours, have tried to design molecular catalysts by employing the more abundant metals, and several complexes of nickel [7,8], cobalt [9-13], copper [14-16] and molybdenum [17-19] have been developed as electrocatalysts for the reduction of acetic acid or water to form $\mathrm{H}_{2}$. Despite much progress in water reduction catalysis, major improvements in several areas, including simplifying structural complexity, increasing catalyst solubility in water, and operating in neutral medium ( $\mathrm{pH} 7.0)$, are needed before efficient electrocatalytic water reduction can be realized. Within this context, we have been designing molecular catalysts based on the water-soluble complexes with simple ligands. As an expanded work [20], reported here is a water-soluble cobalt(II) electrocatalyst, $\left[\mathrm{CoA}_{2}\left(\mathrm{H}_{2} \mathrm{O}\right)_{2}\right] \mathbf{1}$ that can electro-catalyze 
water reduction with a TOF of 350.7 moles of hydrogen per mole of catalyst per hour at an overpotential of $687.6 \mathrm{mV}$ (in buffer, $\mathrm{pH} 7.0$ ). We hope this can establish a new method in water reduction catalysis using inexpensive and earth-abundant material in purely aqueous media.

\section{Experimental sections}

\section{Physical measurements}

Cyclic voltammograms were obtained on a CHI-660E electrochemical analyzer under $\mathrm{N}_{2}$ using a three-electrode cell in which a glassy carbon electrode was the working electrode, a saturated $\mathrm{Ag} / \mathrm{AgCl}$ electrode was the reference electrode, and platinum wire was the auxiliary electrode. Controlled-potential electrolysis (CPE) in aqueous media was conducted using an air-tight glass double compartment cell separated by a glass frit. The working compartment was fitted with a glassy carbon plate and an $\mathrm{Ag} / \mathrm{AgCl}$ reference electrode. The auxiliary compartment was fitted with a Pt gauze electrode. The working compartment was filled with $50 \mathrm{~mL}$ of $0.25 \mathrm{M}$ buffer, while the auxiliary compartment was filled with $35 \mathrm{~mL}$ phosphate buffer solution. Adding cobalt complex, both compartments were sparged for $1 \mathrm{~h}$ with nitrogen and cyclic voltammograms were recorded as controls. After electrolysis, a $0.5 \mathrm{~mL}$ aliquot of the headspace was removed and replaced with $0.5 \mathrm{~mL}$ of $\mathrm{CH}_{4}$. A sample of the headspace was injected into the gas chromatograph (GC). GC experiments were carried out with an Agilent Technologies 7890A gas chromatography instrument. Elemental analyses for $\mathrm{C}, \mathrm{H}$, and $\mathrm{N}$ were obtained on a Perkin-Elmer analyzer model 240. UV-Vis spectra 
were measured on a Hitachi U-3010 spectrometer. ESI-MS experiment was performed on a Bruker Daltonics Esquire 3000 spectrometer by introducing samples directly into the ESI source using a syringe pump. Thermogravimetric (TG) analysis was carried out using a Universal V4 $4 \mathrm{~A}$ Intruments with a heating rate $10^{\circ} \mathrm{C} / \mathrm{min}$ in flowing air. And the Energy Dispersive Spectrometer (EDS) measurement was carried out with a Shimadzu EPMA-1600 Electron Probe X-ray micro analyzer.

\section{Synthesis of complex 1}

To a solution of picolinic acid $(0.246 \mathrm{~g}, 2 \mathrm{mmol})$ in $95 \%$ ethanol $(20 \mathrm{ml}), \mathrm{CoCl}_{2}$. $6 \mathrm{H}_{2} \mathrm{O}(0.238 \mathrm{~g}, 1 \mathrm{mmol})$ in methanol $(5 \mathrm{ml})$ was added and the mixture was stirred for 15 min. Violet crystals were obtained from the filtrate which was allowed to stand at room temperature for several days, collected by filtration, and dried in vacuo $(0.15 \mathrm{~g}$, 40.0\%). The elemental analysis results (Found $\mathrm{C}, 38.27 ; \mathrm{H}, 4.31 ; \mathrm{N}, 7.49$. $\mathrm{C}_{12} \mathrm{H}_{16} \mathrm{CoN}_{2} \mathrm{O}_{8}$ requires $\mathrm{C}, 38.42 ; \mathrm{H}, 4.30 ; \mathrm{N}, 7.47$ ) were in agreement with the formula of the sample used for X-ray analysis.

\section{Crystal structure determination}

The X-ray analysis of $\mathbf{1}$ was carried out with a Bruker Smart Apex II DUO area detector using graphite monochromated Mo-K $\alpha$ radiation $(\lambda=0.71073 \AA)$ at room temperature. All empirical absorption corrections were applied by using the SADABS program [21]. The structure was solved using direct methods and the corresponding non-hydrogen atoms are refined anisotropically. All the hydrogen atoms of the ligands 
were placed in calculated positions with fixed isotropic thermal parameters and included in the structure factor calculations in the final stage of full-matrix least-squares refinement. All calculations were performed using the SHELXTL-97 computer program [22]. Crystallographic data for complex $\mathbf{1}$ are given in Table S1 and selected bond lengths and angles are listed in Table S2.

\section{Results and discussion}

\section{Structural analysis and general characterization}

The reaction of picolinic acid (HA) and $\mathrm{CoCl}_{2} \cdot 6 \mathrm{H}_{2} \mathrm{O}$ formed the cobalt(II) complex, $\left[\mathrm{Co}(\mathrm{A})_{2}\left(\mathrm{H}_{2} \mathrm{O}\right)_{2}\right] \mathbf{1}$, which is soluble both in water and several organic solvents. The UV-Vis spectrum of complex $\mathbf{1}$ was recorded in an aqueous solution, with a main feature at $264 \mathrm{~nm}$ (Fig. S1). The UV-Vis spectra of $\mathbf{1}$ in buffered aqueous solutions in the $\mathrm{pH}$ range of 2.3-11.5 exhibited similar peaks to that in water (Fig. S2), indiacting $\mathbf{1}$ is stable under these conditions.

From Fig. 1, in solid, complex 1 consists of one $\mathrm{Co}^{2+}$ ion, two picolinic acid ions, and two $\mathrm{H}_{2} \mathrm{O}$ molecules. The cobalt atom is six-coordinated by two nitrogen atoms, two oxygen atoms from picolinic acid ions, and two oxygen atoms from two $\mathrm{H}_{2} \mathrm{O}$ molecules. The bond distance of Co and O from picolinic acid (2.0703(17) $\AA$ ) is shorter than that of $\mathrm{Co}$ and $\mathrm{O}$ from $\mathrm{H}_{2} \mathrm{O}(2.144(2) \AA)$. And the $\mathrm{Co}-\mathrm{N}$ distance is 2.119(2) A. Interestingly, $\mathrm{H}_{2} \mathrm{O}$ did not dissociate from cobalt center in methanol, which is in agreement with the result of ESI-MS analysis. The electrospray mass spectrum of 1 exhibited one ion at a mass-to-charge ratio $(\mathrm{m} / \mathrm{z})$ of 340.2823 , with 
mass and isotope distribution pattern corresponding to $\left[\mathrm{Co}(\mathrm{A})_{2}\left(\mathrm{H}_{2} \mathrm{O}\right)_{2}-\mathrm{H}\right]^{+}$(calculated $m / z$ of 340.20) (Fig. S3).

\section{Thermal decomposition process for complex 1}

Fig. 2 illustrated the TG curve of complex $\mathbf{1}$ heat-treated in air using a heating rate of $10{ }^{\circ} \mathrm{C} / \mathrm{min}$ in the temperature range $40-250{ }^{\circ} \mathrm{C}$. The TG of 1 showed marked mass losses with increasing temperature in two steps. The first TG weight loss of approximately $9.70 \%$ in the temperature range $40-120.3{ }^{\circ} \mathrm{C}$ with an endothermic peak at $120.3{ }^{\circ} \mathrm{C}$ is mainly due to the departure of two lattice (theoretical weight loss $9.60 \%$ ) water molecules from complex $\mathbf{1}$. The subsequent thermal decomposition of complex 1 , with a mass loss of $9.60 \%$ in the range $140-170{ }^{\circ} \mathrm{C}$, is contributed to the departure of two (theoretical weight loss 9.60\%) coordination water molecules. No significant weight loss was observed for 1 when the temperature above $170{ }^{\circ} \mathrm{C}$.

\section{Electrochemical studies}

From Fig. 3, in DMF solution at a glassy carbon electrode, complex 1 displayed two quasi-reversible redox couples at -0.34 and $-0.89 \mathrm{~V}$, which can be assigned to the couples of $\mathrm{Co}^{\mathrm{II} / \mathrm{I}}$ and $\mathrm{Co}^{\mathrm{I} / 0}$, respectively. To obtain kinetic information of this complex, CVs were recorded at different scan rates. As shown in Fig. S4, the current responses of the redox events at -0.99 and $-0.48 \mathrm{~V}$ show a linear dependence on the square root of the scan rate, which is an indicative of a diffusion-controlled process, with the electrochemically active species freely diffusing in the solution. 
In aqueous media, complex 1 also exhibited two reduction processes at -0.45 and $-1.43 \mathrm{~V}$, which are assigned to the couples of $\mathrm{Co}^{\mathrm{II} / \mathrm{I}}$ and $\mathrm{Co}^{\mathrm{I} / 0}$, respectively (Fig. 4). To probe the nature of the first reduction process, we investigated the $\mathrm{pH}$ dependence of the cathodic peak potential. The reduction waves were shifted to lower potentials under higher $\mathrm{pH}$, which reflects the shift in the thermodynamic potential for electrocatalysis (Fig. S5a). Fig. S5b showed that $E_{p, a}$ has nearly linear relationship with the $\mathrm{pH}$ values, and a slope of $61 \mathrm{mV}$ per $\mathrm{pH}$ unit was obtained. And the slope of $61 \mathrm{mV}$ per $\mathrm{pH}$ unit is contributed to a $1 \mathrm{e}^{-}-1 \mathrm{H}^{+}$redox process.

\section{Catalytic hydrogen evolution from acetic acid in DMF}

Cyclic voltammogram of $\mathrm{CH}_{3} \mathrm{COOH}$ in the absence of complex $\mathbf{1}$ exhibited no catalytic current at the potentials of the couples of $\mathrm{Co}^{\mathrm{II}} / \mathrm{Co}^{\mathrm{I}}$ and $\mathrm{Co}^{\mathrm{I}} / \mathrm{Co}^{0}$ (Fig. S6), suggesting that proton reduction from $\mathrm{CH}_{3} \mathrm{COOH}$ to $\mathrm{H}_{2}$ occurs with $\mathrm{Co} / \mathrm{Co}^{\mathrm{I}}$ and $\mathrm{Co} / \mathrm{Co}^{0}$. Addition of the varying amounts of $\mathrm{CH}_{3} \mathrm{COOH}$ triggered catalytic currents at potential near the couple of $\mathrm{Co}^{\mathrm{I}} / \mathrm{Co}^{0}$. Fig. 5 showed a systematic increase in $i_{\text {cat }}$ observed near $-0.97 \mathrm{~V}$ with increasing acid concentration from 0.0 to $2.99 \mathrm{mM}$. This clearly establishes that hydrogen evolution electrocatalyzed by $\mathbf{1}$ requires the reduction of $\operatorname{Co}(\mathrm{I})$ to $\operatorname{Co}(0)$. This result is different from the reported result that hydrogen evolution electrocatalyzed by catalyst requires the reduction of $\mathrm{Co}(\mathrm{II})$ to Co(I) and protonation [23,24]. Interestingly, with the acetic acid concentration increased from 0.0 to $2.99 \mathrm{mM}$ (Fig. 5), the onset of the catalytic wave remains almost constant at ca. $-0.24 \mathrm{~V}$ versus $\mathrm{Ag} / \mathrm{AgCl}$. On the basis of literature precedent 
[25] and above analyses, we propose the catalytic cycle depicted in Scheme 1 for the generation of hydrogen from acetic acid mediated by $\mathbf{1}$. Two one-electron reduction of $\left[\mathrm{A}_{2} \mathrm{Co}^{\mathrm{II}}\left(\mathrm{H}_{2} \mathrm{O}\right)_{2}\right] \mathbf{1}$ gives a putative $\left[\mathrm{A}_{2} \mathrm{Co}^{0}\right]^{2-}$ species. Addition of hydrogen proton yields the $\mathrm{Co}^{\mathrm{II}}-\mathrm{H}$ species, a high reactive intermediate. Further addition of hydrogen proton of the Co ${ }^{\mathrm{II}}-\mathrm{H}$ species affords $\mathrm{H}_{2}$, and regenerates the starting complex $\mathbf{1}$. Further mechanistic studies are under investigation.

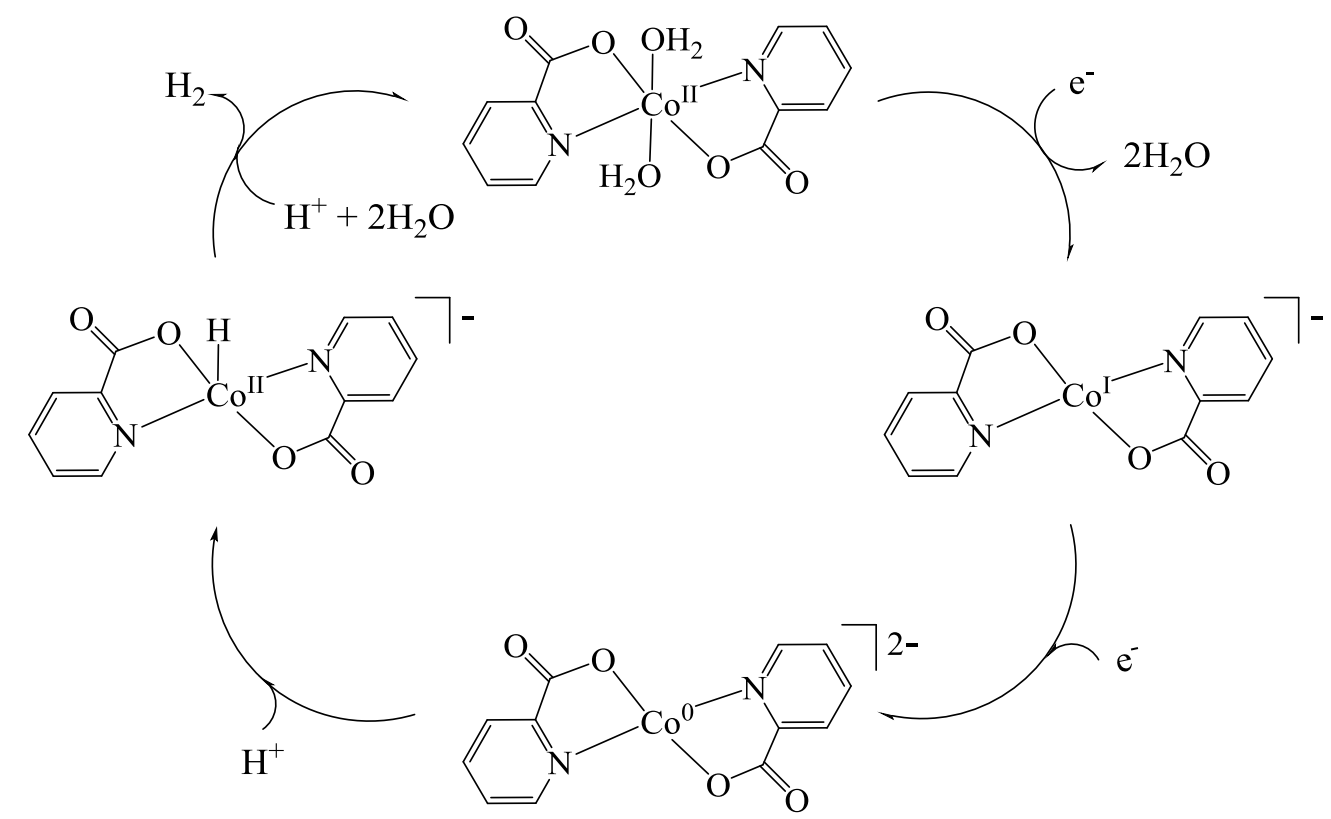

Scheme 1 The possible catalytic mechanism for proton reduction by complex 1

Further evidence for the electro-catalytic activity was obtained by bulk electrolysis of a solution of complex $1(2.5 \mu \mathrm{M})$ in DMF with acetic acid $(3.0 \mathrm{mM})$ at variable applied potential using a glassy carbon plate electrode in a double-compartment cell. Fig. 6a showed the total charge of bulk electrolysis of complex 1 in the presence of acid, when the applied potential was $-1.45 \mathrm{~V}$ versus $\mathrm{Ag} / \mathrm{AgCl}$, the maximum charge reached $71 \mathrm{mC}$ during $2 \mathrm{~min}$ of electrolysis, 
accompanying evolution of a gas, which was confirmed as $\mathrm{H}_{2}$ by gas chromatography. According to Fig. S7, $\sim 0.065 \mathrm{~mL}$ of $\mathrm{H}_{2}$ was produced over an electrolysis period of 2 h. A CPE experiment under the same potential with a catalyst-free only gave a charge of $25 \mathrm{mC}$ (Fig. 6b), showing that this complex does serve an effective hydrogen production under such conditions. According to eq. (1) [18], we calculated TOF for the catalyst reaching a maximum of 42.1 moles of hydrogen per mole of catalyst per hour at an overpotential of $941.6 \mathrm{mV}$ (Eq. S1 and Fig. S8).

$$
\mathrm{TOF}=\Delta C /\left(\mathrm{F}^{*} n_{1} * n_{2} * t\right)
$$

Where, $\Delta C$ is the charge from the pre-catalyst solution during CPE minus the charge from solution without pre-catalyst during CPE; F is Faraday's constant, $n_{1}$ is the number of moles of electrons required to generate one mole of $\mathrm{H}_{2}, n_{2}$ is the number of moles of pre-catalyst in solution, and $\mathrm{t}$ is the duration of electrolysis.

\section{Catalytic water reduction}

As shown in Fig. 4, in the absence of complex 1, a catalytic current was not apparent until a potential of $-1.42 \mathrm{~V}$ versus $\mathrm{Ag} / \mathrm{AgCl}$ was attained. With addition of complex $\mathbf{1}$, the onset of catalytic current was observed at about $-1.0 \mathrm{~V}$ versus $\mathrm{Ag} / \mathrm{AgCl}$, and the current strength increased significantly with increasing concentrations of complex $\mathbf{1}$ from 0.5 to $21.1 \mathrm{mM}$ (Fig. S9).

Several control experiments were then carried out to confirm that complex 1 was indeed responsible for the catalytic reaction. In particular, the free ligand, buffer solution, $\mathrm{CoCl}_{2} \cdot 6 \mathrm{H}_{2} \mathrm{O}$ and the mixture of ligand and $\mathrm{CoCl}_{2} \cdot 6 \mathrm{H}_{2} \mathrm{O}$ were each 
measured under identical conditions. As can be seen in Fig. S10, when the applied potential was $-1.60 \mathrm{~V}$ versus $\mathrm{Ag} / \mathrm{AgCl}$, the maximum charge was only $58 \mathrm{mC}$ during 2 min of electrolysis from a $0.25 \mathrm{M}$ buffer. Addition of $\mathrm{HA}$ or $\mathrm{CoCl}_{2} \cdot 6 \mathrm{H}_{2} \mathrm{O}$ led to a slight increase in $\mathrm{H}_{2}$ evolution at $93 \mathrm{mC}$ and $108 \mathrm{mC}$, respectively. However, the addition of the mixture of $\mathrm{HA}$ and $\mathrm{CoCl}_{2} \cdot 6 \mathrm{H}_{2} \mathrm{O}$ led to a significant increase in $\mathrm{H}_{2}$ evolution at $370 \mathrm{mC}$. Thus, a combination of the cobalt center and the ligand is essential for catalytic activity. Under the same conditions, the charge reached 1288 $\mathrm{mC}$ with addition of complex $\mathbf{1}$ (Fig. S10), accompanying a large amount of gas bubble appeared, which was confirmed to be $\mathrm{H}_{2}$ by GC analysis. The evolved $\mathrm{H}_{2}$ was analyzed by gas chromatography, Fig. S11a, which gave $227.24 \mathrm{~mL}$ of $\mathrm{H}_{2}$ over an electrolysis period of $1 \mathrm{~h}$ with a Faradaic efficiency of $95.4 \%$ for $\mathrm{H}_{2}$ (Fig. S11b). Fig. 7 showed the total charge of bulk electrolysis of complex 1 under a series of applied potentials, according to $E q$. (1), we calculated TOF for the catalyst reaching a maximum of 350.7 moles of hydrogen per mole of catalyst per hour an overpotential of $687.6 \mathrm{mV}$ (Eq. S2 and Fig. S12). To the best of our knowledge, this value is higher than some reported molecular catalysts for electrochemical hydrogen production from neutral water, including a cobalt(II) complex with 2-tetrahydrofurfurylamino-N,N-bis(2-methylene-4-tert-butyl-6-methyl)phenol that exhibits a turnover frequency of 15 moles of $\mathrm{H}_{2}$ per mole of catalyst per hour at an overpotential of $689 \mathrm{mV}$ [26] and a cobalt complex with macrocyclic ligand displaying a turnover number of 5 moles of $\mathrm{H}_{2}$ per mole of catalyst with a turnover number of 0.4 moles of $\mathrm{H}_{2}$ per mole of catalyst per hour at an overpotential of 390 
$\mathrm{mV}$ [27], and yet lower than the recently reported cobalt based one [28]. This is attributed to the ionic ligand, $\mathrm{A}^{-}$, that coordinates through two nitrogen atoms and two oxygen atoms to the cobalt center, leaving two $\mathrm{H}_{2} \mathrm{O}$ molecules trans-relative positions and stabilizing $\operatorname{Co}(0)$. On the basis of above analyses, efficient water reduction catalysts (WRCs) generally prefer softer ligands to generate low-valent active intermediates that can reduce protons at low over-potentials, such as oxime [29-31], and phosphine [32] ligands.

\section{Investigation of the stability and durability of complex 1}

In order to determine whether $\mathbf{1}$ retains activity for water reduction over longer time periods, a $72 \mathrm{~h}$ controlled-potential electrolysis at $-1.45 \mathrm{~V}$ vs $\mathrm{Ag} / \mathrm{AgCl}$ was conducted in a stirred 0.25 M buffer solution ( $\mathrm{pH} 7.0)$, containing $1(6.67 \mu \mathrm{M})$. As shown in Fig. $\mathrm{S} 13$, a total of $5605 \mathrm{C}$ was passed during the electrolysis. This catalyst afforded a charge build-up over time, with no substantial loss in activity over the course of $72 \mathrm{~h}$. After a $72 \mathrm{~h}$ electrolysis period, $\mathrm{pH}$ increases by 5.5 units (from 7.0 to 12.5), consistent with accumulation of $\mathrm{OH}^{-}$by water reduction, $2 \mathrm{H}_{2} \mathrm{O}+2 \mathrm{e} \rightarrow \mathrm{H}_{2}+2 \mathrm{OH}^{-}$. Interestingly, the original catalytic function was recovered and could be repeated several times when the solution $\mathrm{pH}$ was adjusted back to the original 7.0.

In order to prove complex $\mathbf{1}$ as a homogeneous electrocatalyst, we obtained dependence of the catalytic current on concentration of complex 1. As shown in Fig. S9, the observation of the catalytic current being dependent of complex 1 concentration could indicate a homogeneous catalyst. And several pieces of 
evidence also suggested that this cobalt complex is a homogeneous catalyst: 1) There is no evidence for a heterogeneous electrocatalytic deposit. 2) No discoloration of the electrodes was observed during cyclic voltammetry or bulk electrolysis. 3) At a glassy carbon electrode, there was no evidence for precipitation formation by EDS (Fig. S14) after a 3 h electrolysis period.

\section{Conclusion}

In summary, a water soluble cobalt(II) complex 1, which is very easy to be obtained, can catalyze water reduction with a TOF of 350.7 moles of hydrogen per mole of catalyst per hour at an overpotential of $687.6 \mathrm{mV}(\mathrm{pH} \mathrm{7.0)}$. This discovery has established a new chemical paradigm for creating water reduction catalysts that is highly active in purely aqueous media. 


\section{Acknowledgements}

This work was supported by the National Science Foundation of China (No. 20971045 and 21271073).

\section{REFERENCES}

[1] Walter MG, Warren EL, McKone JR, Boettcher SW, Mi QX, Santori EA, et al. Solar water splitting cells. Chem Rev 2010; 110: 6446 - 73

[2] McKone JR, Marinescu SC, Brunschwig BS, Winkler JR, Gray HB. Earth-abundant hydrogen evolution electrocatalysts, Chem Sci 2014; 5: 865-78.

[3] $\mathrm{Hu} \mathrm{X}$, Brunschwig BS, Peters JC, Electrocatalytic hydrogen evolution at low overpotentials by cobalt macrocyclic glyoxime and tetraimine complexes. J Am Chem Soc 2007; 129: 8988-98.

[4] Chen HM, Chen CK, Liu RS, Zhang L, Zhang JJ, Wilkinson DP. Nano-architecture and material designs for water splitting photoelectrodes. Chem Soc Rev 2012; 41: 5654-71

[5] Cook TR, Dogutan DK, Reece SY, Surendranath Y, Teets TS, Nocera DG. Solar energy supply and storage for the legacy and nonlegacy worlds. Chem Rev 2010; 110: 6474-6502.

[6] Suntivich J, May KJ, Gasteiger HA, Goodenough JB, Shao-Horn YA. A perovskite oxide optimized for oxygen evolution catalysis from molecular orbital principles. Science 2011; 334: 1383-85. 
[7] Helm ML, Stewart MP, Bullock RM, DuBois MR, DuBois DL, A synthetic nickel electrocatalyst with a turnover frequency above $100,000 \mathrm{~s}^{-1}$ for $\mathrm{H}_{2}$ production. Science 2011; 333: 863-66.

[8] Cao JP, Fang T, Fu LZ, Zhou LL, Zhan SZ. A nickel molecular electro-catalyst for generating hydrogen from acetic acid or water. Int J Hydrogen Energy 2014; 39: $10980-86$

[9] Sun Y, Bigi JP, Piro NA, Tang ML, Long JR, Chang CJ. Molecular cobalt pentapyridine catalysts for generating hydrogen from water. J Am Chem Soc 2011; 133: $9212-15$

[10] Fu LZ, Zhou LL, Tang LZ, Zhang YX, Zhan SZ. Electrochemical and photochemical-driven hydrogen evolution catalyzed by a dinuclear $\mathrm{Co}^{\mathrm{II}}-\mathrm{Co}^{\mathrm{II}}$ complex. J Power Sources 2015; 280: 453-458

[11] Stubbert BD, Peters JC, Gray HB. Rapid water reduction to $\mathrm{H}_{2}$ catalyzed by a cobalt bis(iminopyridine) complex. J Am Chem Soc 2011; 133: 18070-73.

[12] Singh WM, Baine T, Kudo S, Tian S, Ma XAN, et al. Electrocatalytic and photocatalytic hydrogen production in aqueous solution by a molecular cobalt complex. Angew Chem Int Ed 2012; 51: 5941-44.

[13] Fang T, Fu LZ, Zhou LL, Zhan SZ. A water-soluble dinuclear copper electrocatalyst, $\left[\mathrm{Cu}(\mathrm{oxpn}) \mathrm{Cu}(\mathrm{OH})_{2}\right]$ for both water reduction and oxidation. Electrochimica Acta 2015; 161: 388-394.

[14] Fu LZ, Fang T, Zhou LL, Zhan SZ. A mononuclear copper electrocatalyst both water reduction and oxidation. RSC Adv 2014; 4: 53674-80 
[15] Cao JP, Fang T, Fu LZ, Zhou LL, Zhan SZ. First mononuclear copper(II) electro-catalyst for catalyzing hydrogen evolution from acetic acid and water. Int $\mathbf{J}$. Hydrogen Energy 2014; 39: 13972-78

[16] Zhou LL, Fang T, Cao JP, Zhu Z, Su X, Zhan SZ. A dinuclear copper(II) electrocatalyst both water reduction and oxidation. J Power Sources 2015; 273: 298-304

[17] Karunadasa HI, Chang CJ, Long JR. A molecular molybdenum-oxo catalyst for generating hydrogen from water. Nature 2010; 464: 1329-33.

[18] Cao JP, Fang T, Zhou LL, Fu LZ, Zhan SZ. A molecular molybdenum electrocatalyst for generating hydrogen from acetic acid or water. J Power Sources 2014; 272: 169-175

[19] Cao JP, Fang T, Zhou LL, Fu LZ, Zhan SZ. A molecular molybdenum-schiff base electro-catalyst for generating hydrogen from acetic acid or water. Electrochimica Acta 2014; 147: 129-135

[20] Wang ZQ, Tang LZ, Zhang YX, Zhan SZ, Ye JS. Electrochemical-driven water splitting catalyzed by a water-soluble cobalt(II) complex supported by $\mathrm{N}, \mathrm{N}$ '-bis(2'-pyridinecarboxamide)-1,2-benzene with high turnover frequency, J Power Sources 2015; 287: 50-57.

[21] Sheldrick GM, SADABS, Program for Empirical Absorption Correction of Area Detector Data, University of Götingen, Götingen, Germany, 1996.

[22] Sheldrick GM, SHELXS 97, Program for Crystal Structure Refinement, University of Götingen, Götingen, Germany, 1997. 
[23] McKone JR, Marinescu SC, Brunschwig BS, Winkler JR, Gray HB. Earth-abundant hydrogen evolution electrocatalysts. Chem Sci 2014; 5: 865-78.

[24] Bhattacharjee A, Andreiadis ES, Chavarot-Kerlidou M, Fontecave M, Field MJ, Artero V. A computational study of the mechanism of hydrogen evolution by cobalt(diimine-dioxime) catalysts. Chem Eur J 2013; 19: 15166-74.

[25] Rodenberg A, Orazietti M, Probst B, Bachmann C, Alberto R, Baldridge KK, Hamm P. Mechanism of photocatalytic hydrogen generation by a polypyridyl-based cobalt catalyst in aqueous solution. Inorg Chem 2015; 54: 646-57.

[26] Lin CN, Zhou LL, Fu LZ, Zhan SZ, Chen CH. Synthesis, structure and electrochemical properties of a cobalt(II) complex supported by 2-tetrahydrofurfurylamino-N,N-bis(2-methylene-4-tert-butyl-6-methyl)phenol. Inorg Chem Commun 2015; 61: 97-9.

[27] Bernhardt PV, Jones LA. Electrochemistry of macrocyclic cobalt(III/II) Hhexaamines: Electrocatalytic hydrogen evolution in aqueous solution. Inorg Chem 1999; 38: 5086-90.

[28] Cao JP, Fu LZ, Zhou LL, Zhan SZ. Electrochemical-driven hydrogen evolution from acetic acid and water catalyzed by a mixed-valent $\mathrm{Co}^{\mathrm{II}}-\mathrm{Co}^{\mathrm{I}}$ complex with high turnover frequency. J Power Sources 2015; 279: 107-113.

[29] Dempsey JL, Brunschwig BS, Winkler JR, Gray HB. Hydrogen evolution catalyzed by cobaloximes. Acc Chem Res 2009; 42: 1995-2004.

[30] Razavet M, Artero V, Fontecave M. Proton electroreduction catalyzed by cobaloximes: Functional models for hydrogenases. Inorg Chem 2005; 44: 4786-95. 
[31] Hu X, Brunschwig BS, Peters JC. Electrocatalytic hydrogen evolution by cobalt difluoroboryl-diglyoximate complexes. Chem Commun 2005; 4723-25.

[32] Koelle U, Ohst S. Electrochemical reduction of protonated cyclopentadienylcobalt phosphine complexes. Inorg Chem 1986; 25: 2689-94. 


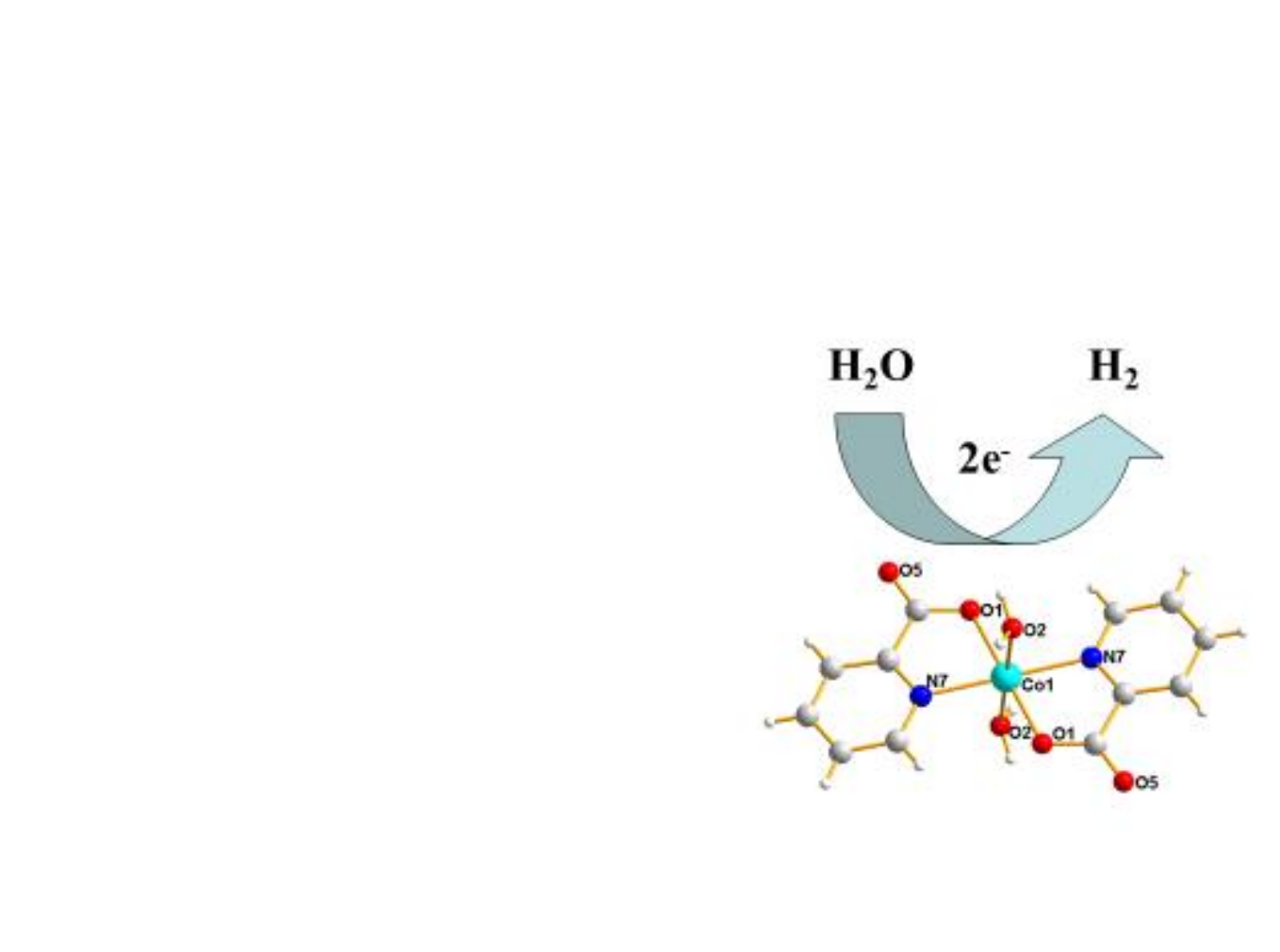

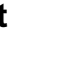

.
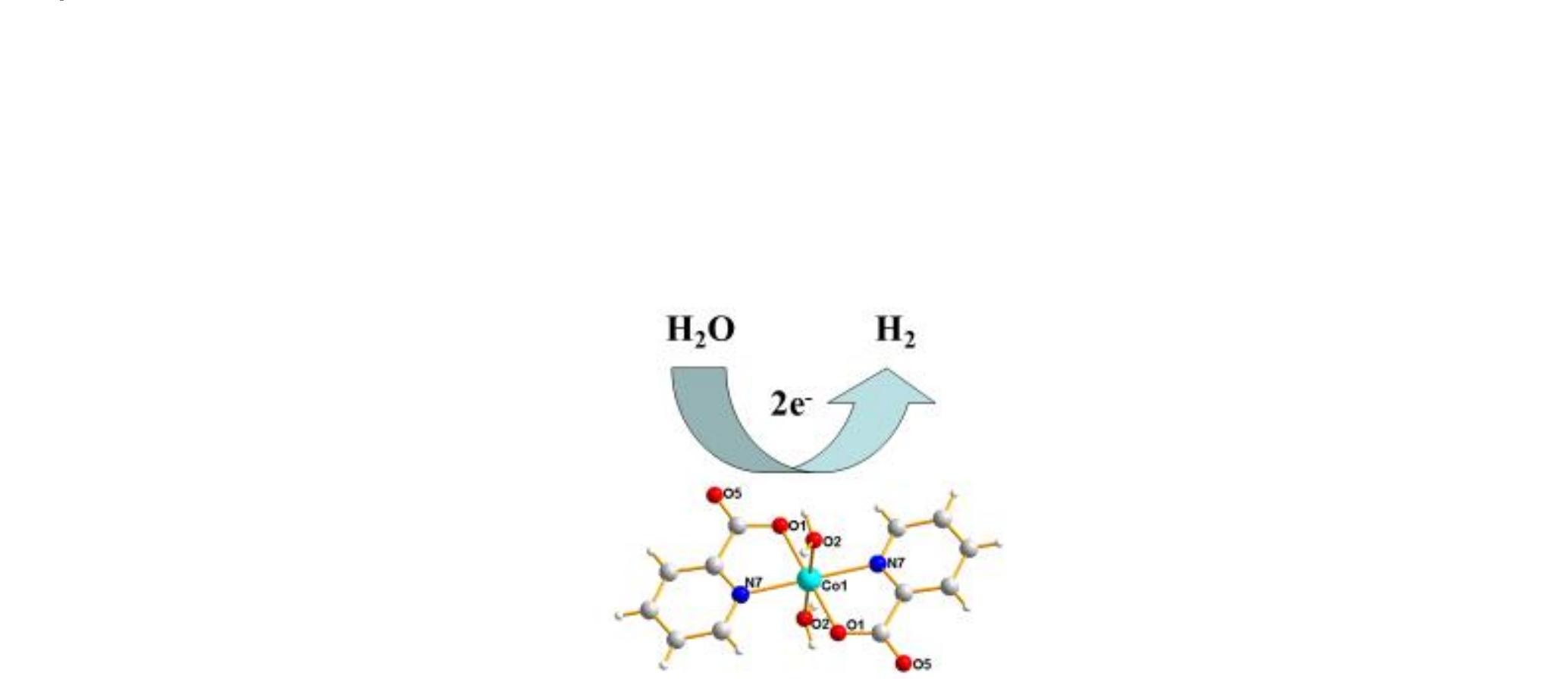

.

.

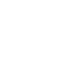

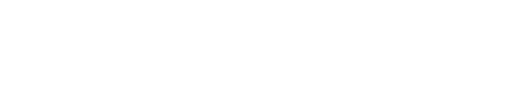




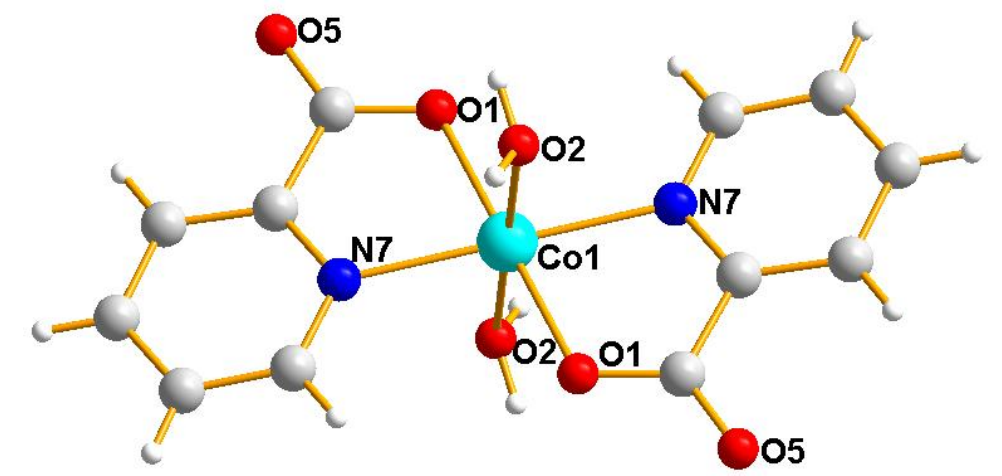

Fig. 1 - X-ray molecular structure of complex 1 


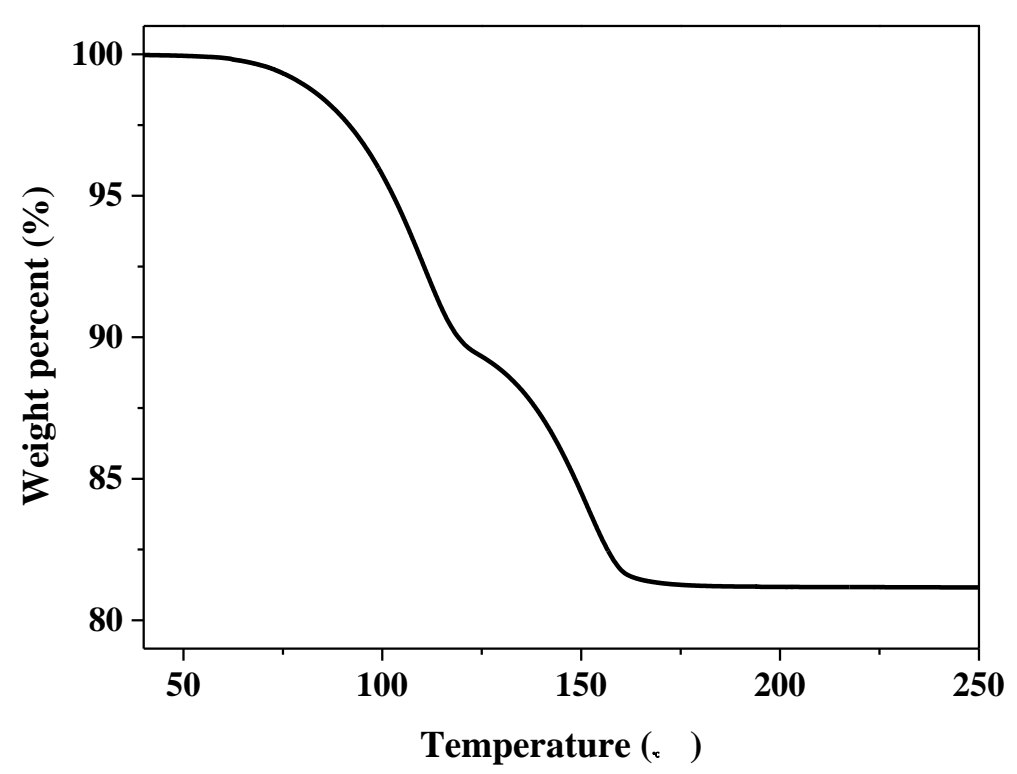

Fig. 2 - The TG curve of complex 1

\author{
Hig. 2 - The TG curve of complex 1
}




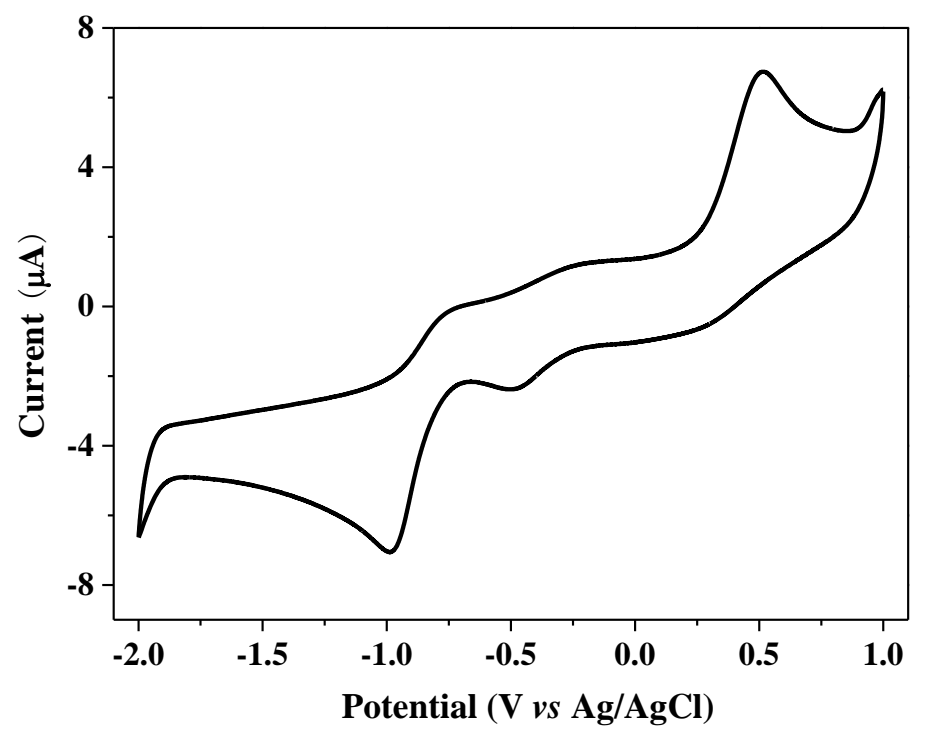

Fig. 3 - Cyclic voltammogram of $0.25 \mathrm{mM}$ complex 1 in $0.10 \mathrm{M}$ of $\left[\mathrm{n}-\mathrm{Bu}_{4} \mathrm{~N}\right] \mathrm{ClO}_{4}$ DMF solution at a glassy carbon electrode and a scan rate of $100 \mathrm{mV} / \mathrm{s}$. 


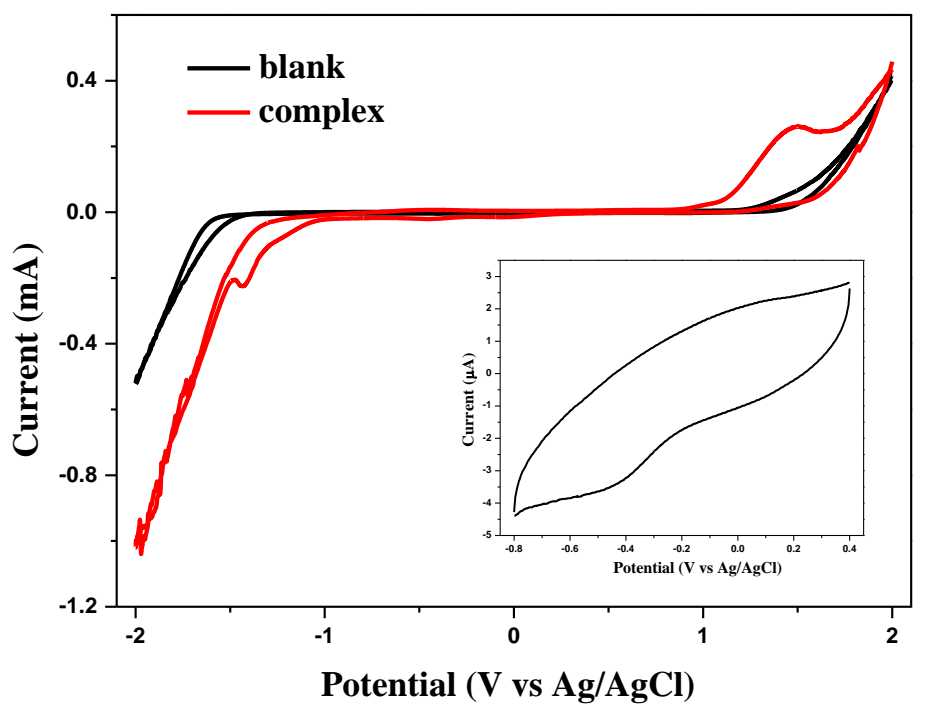

Fig. 4 - Cyclic voltammogram of complex $1(1.76 \mathrm{mM})$ in $0.10 \mathrm{M} \mathrm{KCl}$ at a glassy carbon electrode and a scan rate of $100 \mathrm{mV} / \mathrm{s}$. The inset shows a magnified view of the $\mathrm{Co}^{\mathrm{II}} / \mathrm{Co}^{\mathrm{I}}$ couple. 


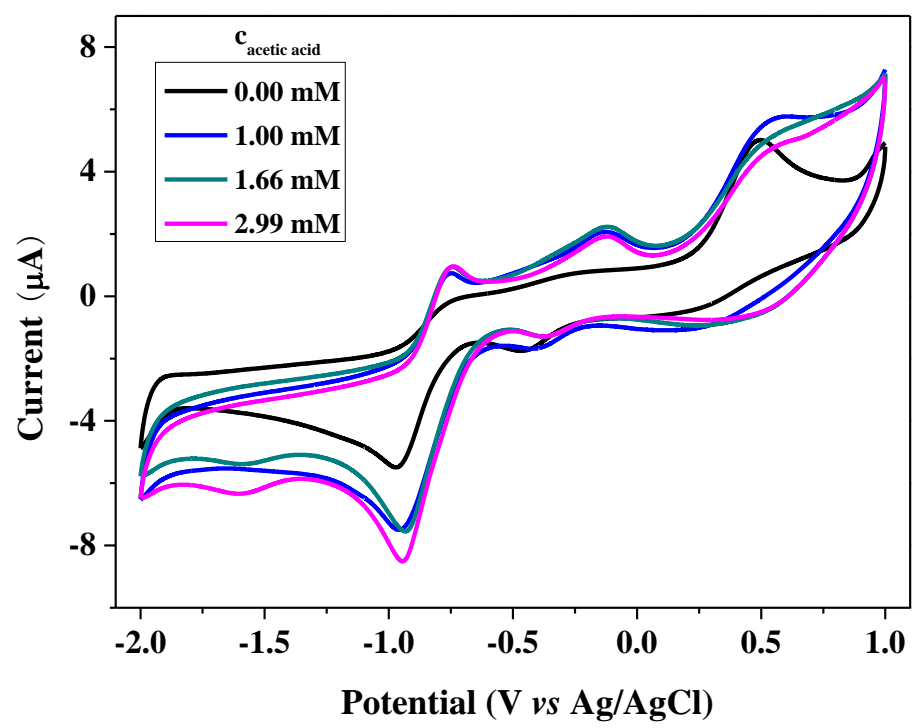

Fig. 5 - Cyclic voltammograms of a $0.25 \mathrm{mM}$ solution of complex 1, with varying concentrations of acetic acid in DMF. Conditions: $0.10 \mathrm{M}\left[\mathrm{n}-\mathrm{Bu}_{4} \mathrm{~N}\right] \mathrm{ClO}_{4}$ as supporting electrolyte, scan rate: $100 \mathrm{mV} / \mathrm{s}$, glassy carbon working electrode $(1 \mathrm{~mm}$ diameter), $\mathrm{Pt}$ counter electrode, $\mathrm{Ag} / \mathrm{AgCl}$ reference electrode. 

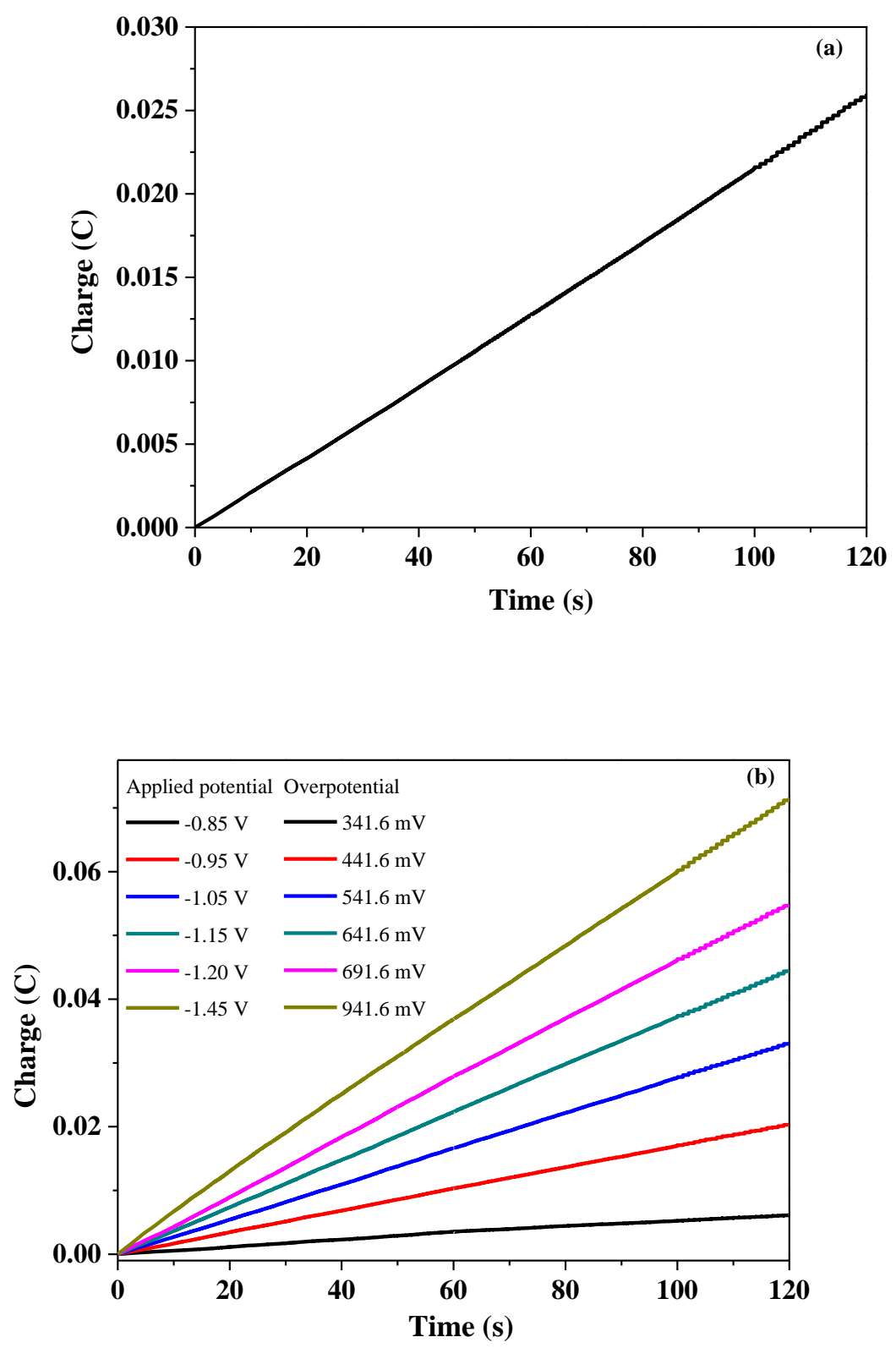

Fig. 6 - (a) Charge buildup versus time from electrolysis of a $2.5 \mu \mathrm{M}$ complex 1 solution in DMF $\left(0.10 \mathrm{M}\left[\mathrm{n}-\mathrm{Bu}_{4} \mathrm{~N}\right] \mathrm{ClO}_{4}\right)$ under various applied potentials. All data have been deducted blank. (b) Charge buildup versus time from electrolysis of a 3.0 $\mathrm{mM}$ acetic acid in DMF $\left(0.10 \mathrm{M}\left[\mathrm{n}-\mathrm{Bu}_{4} \mathrm{~N}\right] \mathrm{ClO}_{4}\right)$ under $1.45 \mathrm{~V}$ versus $\mathrm{Ag} / \mathrm{AgCl}$. 


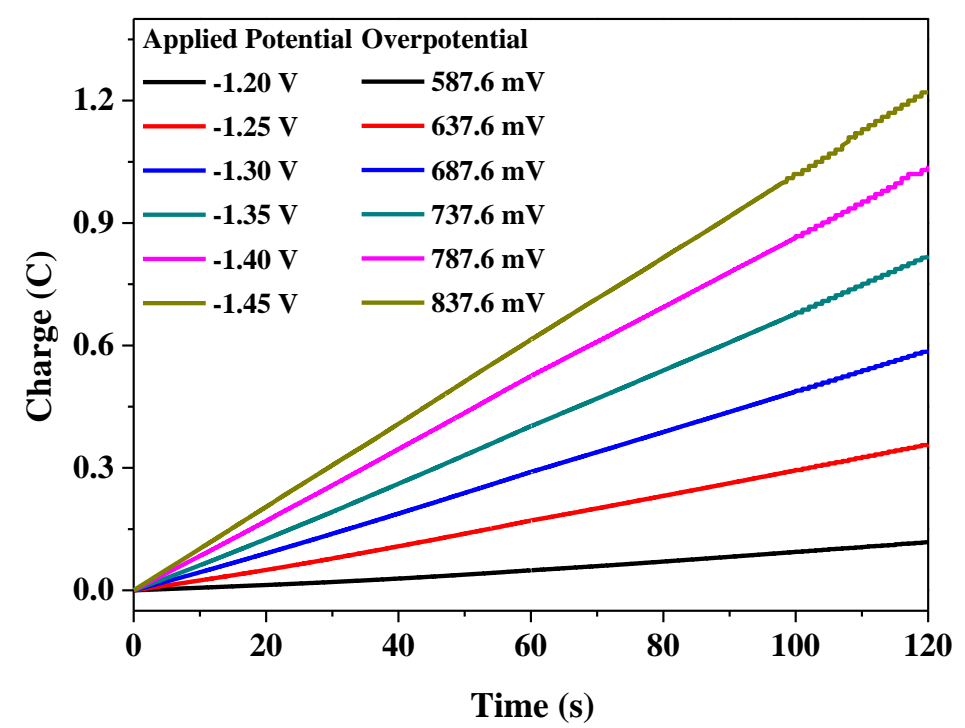

Fig. 7 - Charge buildup versus time from the electrolysis of a $6.67 \mu \mathrm{M}$ solution in $0.25 \mathrm{M}$ buffer at $\mathrm{pH} 7.0$ under various applied potentials. All data have been deducted blank. 